\title{
Compressive Strength and Durability Properties of Lightweight Concrete Bricks under Full Water Curing and Air-Dry Curing
}

\author{
Ling I.H, Teo D.C.L \\ Faculty of Engineering \\ Universiti Malaysia Sarawak \\ 94300 Kota Samarahan, Malaysia
}

\begin{abstract}
Due to the serious environmental pollution and the production of huge energy consuming building materials, the development of new eco-friendly and energy saving building materials to overcome these issues has been gaining increased attention. This paper presents the potential use of both agricultural and industrial wastes namely Rice Husk Ash (RHA) and Expanded Polystyrene (EPS) respectively as raw material for the production of 'Green' lightweight concrete bricks. RHA was used as partial cement replacement, while the EPS was used as partial aggregate replacement in the mixes. In this investigation, the control sample with a Cement: Sand: EPS ratio of 1.0: 1.5: 1.5 was first produced. The cement in the sample was then replaced by $5 \%$, $10 \%, 15 \%$ and $20 \%$ of RHA. A w/c ratio of 0.5 was used throughout this investigation. Full water curing and air-dry curing conditions were employed in this investigation. The properties investigated were slump, fresh concrete density, air content, compressive strength, water absorption, sorptivity and thermal conductivity. It was determined that EPS RHA concrete brick gives promising results.
\end{abstract}

\section{Introduction}

Brick is a major building material in construction industry. For decades, conventional clay bricks are widely being utilized in many types of construction especially to form walls for buildings. However, the use of clay bricks caused the ongoing mining of clay soil which is not sustainable for the industry. Besides that, the brick production process consumed high energy such as burning of fossil fuels. Cement bricks came to the industry later which provides more solutions for the industry.

The problem of accumulation of unmanaged solid waste is an environmental issue concerned by the world today. Industrial solid waste namely expanded polystyrene beads (EPS) and agricultural waste namely rice husk ash (RHA) have been facing a serious problem for disposal. Normally, these waste materials are burnt or sent to landfills. The burning of these waste materials posses serious air pollution.
In addition, the disposal of EPS in landfills also does not provide an environmental friendly solution since EPS is not biodegradable.

In light of the escalating concerns for environmental issues, the concept of sustainable development and energy conservation has become of paramount importance. One such method is through the introduction of recycling solid wastes into useful supplementary raw materials for new building materials.

Rice husk is an agro-waste abundantly available in rice producing countries. It constitutes about $20 \%$ of the weight of rice. When burnt, $20 \%$ of rice husk's weight remains as a waste material in the form of RHA. RHA contains high amount of silica [1]. It is a highly pozzolanic material which combines quickly with calcium hydroxide $(\mathrm{CH})$ forming a secondary calcium silicate hydrate $(\mathrm{C}-\mathrm{S}-\mathrm{H})$ [1]. Therefore, it is a suitable mineral admixture for cement and concrete [2].

Expanded polystyrene (EPS) waste is a byproduct from the packaging industry. It is one of many lightweight, low strength materials with good energy absorbing characteristic. It is well known for its good thermal and acoustic insulation properties leading mainly to non-structural applications including precast roof and wall panels and lightweight infill blocks [3]. It can easily be incorporated in mortar or concrete to produce lightweight concrete, with a wide range of densities [4].

In this study, solid waste namely EPS and RHA were used as partial replacement for cement and aggregate respectively in order to produce 'Green' lightweight concrete bricks. The fundamental engineering properties namely compressive strength, sorptivity, water absorption and thermal conductivity of the brick specimens were investigated.

\section{Experimental works}

\subsection{Materials}

\subsubsection{RHA}

RHA was obtained from Sufficients Agricultural Co. Ltd, Thailand. The specific gravity, surface area 
(nitrogen absorption BET) and fineness as retained on $45 \mu \mathrm{m}$ sieve for the RHA were $2.02,20220 \mathrm{~m}^{2} / \mathrm{kg}$ and $14 \%$ respectively. The ash was ground using a Los Angeles grinding machine until it met the ASTM C 618 [5] fineness specification. Its loss of ignition (LOI), silica content and bulk density were $6.78 \%, 87.97 \%$ and $480 \mathrm{~kg} / \mathrm{m}^{3}$ respectively. X-ray diffraction (XRD) analysis was carried out and the results confirmed that RHA was mainly in amorphous silica formation.

\subsubsection{EPS}

The EPS were collected from Saplastic Packaging (Sarawak) Sdn Bhd. Figure 1 shows the grading for the EPS. Figure 2 shows the RHA and EPS used in this investigation.

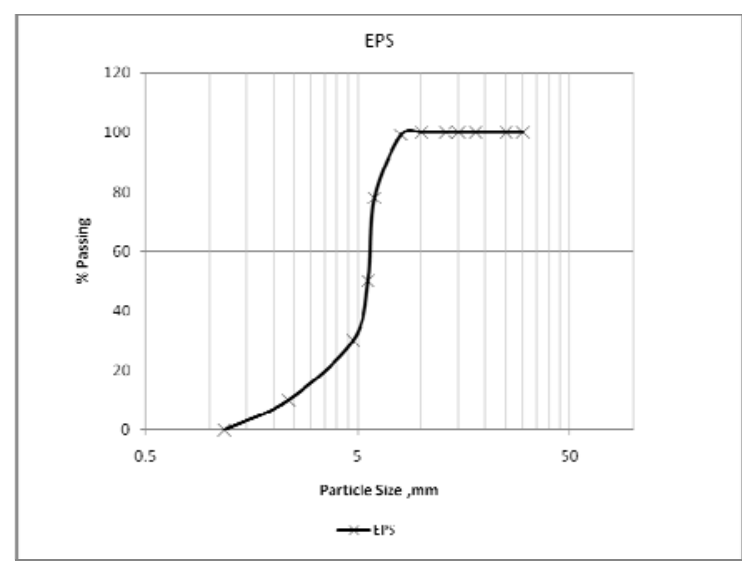

Figure 1: Grading curve for EPS

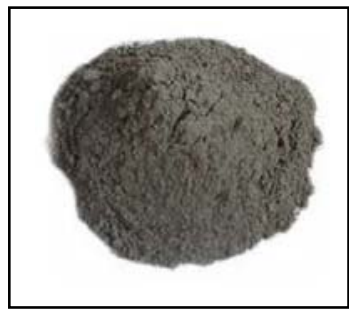

(a)

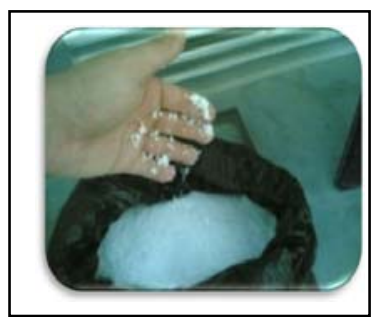

(b)
Figure 2: (a) RHA and (b) EPS

\subsubsection{Other materials}

Locally produced Ordinary Portland Cement Type I conforming to Malaysian Standard specification MS 522: Part 1: 2003 [6] was used in this entire investigation. Its specific gravity and specific surface (Blaine) were 3.05 and $3500 \mathrm{~m}^{2} / \mathrm{kg}$ respectively. A superplasticizer was used to improve the workability of the mix. The superplaticizer used was a Glenium C380 Type F admixture. The amount of superplasticizer used was $800 \mathrm{ml}$ per $100 \mathrm{~kg}$ of cement. Potable tap water was used for mixing and curing in this experiment.

\subsection{Mixture}

Five different EPS RHA concrete brick mixtures were produced, tagged as A, B, C, D and E. Due to the lightweight nature of EPS and RHA, all mix proportions were produced by volume. Sample A acts as control sample which contained only cement, sand and EPS. This control sample has cement of $425 \mathrm{~kg} / \mathrm{m}^{3}$, sand of $542 \mathrm{~kg} / \mathrm{m}^{3}$ and EPS of $219 \mathrm{~kg} / \mathrm{m}^{3}$. Samples B, C, D and E have RHA replacement with cement in different percentages of 5, 10, 15 and 20 $\%$ respectively by mass of cement and with the same volume of sand and EPS. The water-cement ratio is maintained at 0.5 for all mixes. The mix proportion for each sample is shown in Table 1.

Table 1: Mix Proportions

\begin{tabular}{clcccl}
\hline \multirow{2}{*}{ Samples } & \multicolumn{3}{l}{ Ratio (by volume) } & Water- \\
\cline { 2 - 5 } & Cement & RHA & Sand & EPS & $\begin{array}{l}\text { Cement } \\
\text { ratio }\end{array}$ \\
\hline A & 1.00 & 0 & 1.5 & 1.5 & \\
B & 0.95 & 0.05 & 1.5 & 1.5 & \\
C & 0.90 & 0.10 & 1.5 & 1.5 & 0.5 \\
D & 0.85 & 0.15 & 1.5 & 1.5 & \\
E & 0.80 & 0.20 & 1.5 & 1.5 &
\end{tabular}

The required amount of fresh concrete to prepare the test samples was mixed in a pan mixer with a capacity of 40 litres. Once a uniform mixture is formed, the fresh concrete was placed into the respective plywood moulds. After casting, the specimens were covered with plastic sheet to avoid excess evaporation. The specimens were demoulded after $24 \pm 3$ hours of casting and left to cure until the day of testing. All the samples had a 28-day air-dry density of less than $1850 \mathrm{~kg} / \mathrm{m}^{3}$ which classifies them as lightweight concrete [7].

\subsection{Curing conditions}

Two types curing conditions as shown in Table 2 were incorporated to study the effect of curing environment on the performance of EPS RHA concrete bricks.

Table 2: Curing Regimes

\begin{tabular}{|c|c|c|c|c|c|}
\hline \multirow{2}{*}{$\begin{array}{l}\text { Curing } \\
\text { method }\end{array}$} & \multirow{2}{*}{$\begin{array}{l}\text { Temperature } \\
\left({ }^{\circ} \mathrm{C}\right)\end{array}$} & \multirow{2}{*}{$\begin{array}{l}\text { RH } \\
\text { (\%) }\end{array}$} & \multicolumn{3}{|c|}{$\begin{array}{l}\text { Duration of Curing } \\
\text { (day) }\end{array}$} \\
\hline & & & Mould & Water & Air \\
\hline $\begin{array}{l}\text { Full } \\
\text { water }\end{array}$ & $24 \pm 2$ & 100 & 1 & UAT* & 0 \\
\hline Air-dry & $26 \pm 3$ & $73 \pm 5$ & 1 & 0 & UAT* \\
\hline
\end{tabular}




\section{Test methods}

\subsection{Fresh concrete properties}

The fresh concrete properties investigated under this study include workability [8], fresh density [9] and air content [10].

\subsection{Hardened concrete properties}

The hardened concrete properties for EPS RHA concrete bricks were compressive strength [11], sorptivity [12], water absorption [13] and thermal conductivity [14]. All samples were tested at 3, 7 and 28 days and the results were reported as an average of three tested samples. Bricks of size $215 \mathrm{~mm} \mathrm{x}$ $102.5 \mathrm{~mm} \times 65 \mathrm{~mm}$ were used for compressive strength test. Specimen size of $100 \mathrm{~mm}$ x $100 \mathrm{~mm} \times$ $100 \mathrm{~mm}$ was prepared for the sorptivity test while specimen size of $300 \mathrm{~mm} \times 300 \mathrm{~mm} \times 60 \mathrm{~mm}$ was prepared for thermal conductivity test.

\section{Results and discussions}

\subsection{Fresh concrete properties}

The results of the fresh concrete properties are presented in Table 3. The results demonstrate the tendency of slump to decrease as the RHA ratio increases. The decline in the slump values can be related to the high porosity of the RHA particles as represented by the high specific surface area and LOI value which caused the mix become drier. The fresh concrete density was in range of $1750-1838 \mathrm{~kg} / \mathrm{m}^{3}$. The experimental results indicated that the increased amount of RHA in the mixes produced higher percentage of air content for the mixes. It is due to the porous nature of the RHA which induces more pores in the concrete mix. The air content for the all mixes was within the acceptable range of $4-8 \%$ as stipulated by ACI 213R [7].

Table 3: Fresh concrete properties

\begin{tabular}{cccc}
\hline Samples & $\begin{array}{c}\text { Slump } \\
\text { height, } \\
(\mathbf{m m})\end{array}$ & $\begin{array}{c}\text { Air } \\
\text { content, \% }\end{array}$ & $\begin{array}{c}\text { Fresh } \\
\text { concrete } \\
\text { density, } \\
\left.\text { (kg/m } \mathbf{m}^{3}\right)\end{array}$ \\
\hline A & 100 & 5.2 & 1838 \\
B & 90 & 5.5 & 1810 \\
C & 80 & 6.1 & 1790 \\
D & 70 & 6.5 & 1770 \\
E & 65 & 6.9 & 1750 \\
\hline
\end{tabular}

\subsection{Compressive strength}

The compressive strength of the EPS RHA concrete bricks at 3, 7 and 28 days under full water and air-dry curing are presented in Figure 3 and Figure 4. Due to the high reactivity of RHA as exhibited by the high content of amorphous silica and large specific surface area of $20220 \mathrm{~m}^{2} / \mathrm{kg}$, which indicates the porous structures [15], all the concrete bricks with RHA replacement showed higher compressive strength the early age (3 days) as compared to control sample. This is consistent with the findings of other researchers [16]. According to the test results, sample C with $10 \%$ RHA replacement showed the highest compressive strength under both full water curing and air-dry curing at all ages.

From the result obtained, the highest 28-day compressive strength value of $17.51 \mathrm{~N} / \mathrm{mm}^{2}$ was obtained from the mix made of $10 \%$ RHA replacement (Sample C). This represents an increase in compressive strength of up to $25.75 \%$ as compared to the control sample under full water curing. As expected, full water curing produced highest compressive strength at all ages for all samples as compared to air-dry curing condition. However, all brick samples achieved the minimum compressive strength of $7 \mathrm{~N} / \mathrm{mm}^{2}$ according to MS76:1972 [11] for Class 1 load bearing purposes.

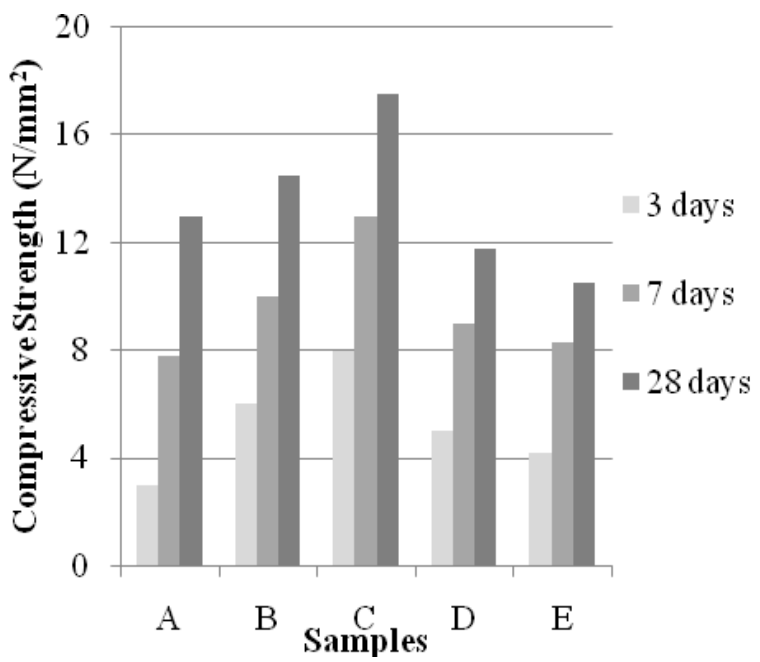

Figure 3: Compressive strength for different samples under full water curing 


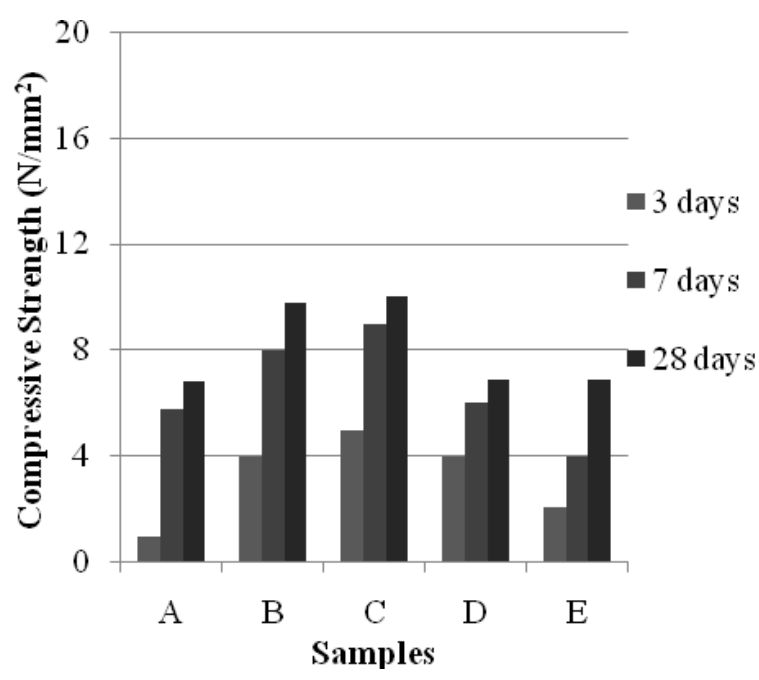

Figure 4: Compressive strength for different samples under air-dry curing

\subsection{Sorptivity}

Sorptivity is a material property that describes the tendency of porous material to absorb and transmit water by capillary suction [17]. As expected, the concrete bricks under air dry curing had higher sorptivity than those samples cured in full water curing. The sorptivity values for full water and air dry curing were in the range of 0.075 $0.145 \mathrm{~mm} / \mathrm{min}^{0.5}$ and $0.113-0.186 \mathrm{~mm} / \mathrm{min}^{0.5}$ at 28 day age respectively. The sorptivity values of the EPS RHA concrete bricks at 3, 7 and 28 days under full water and air-dry curing are presented in Figure 5 and Figure 6.

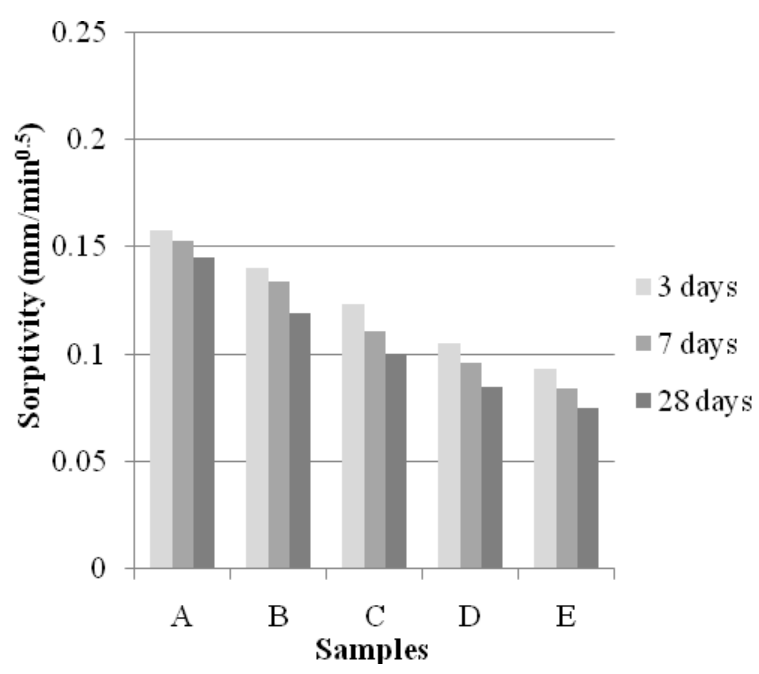

Figure 5: Sorptivity for different samples under full water curing

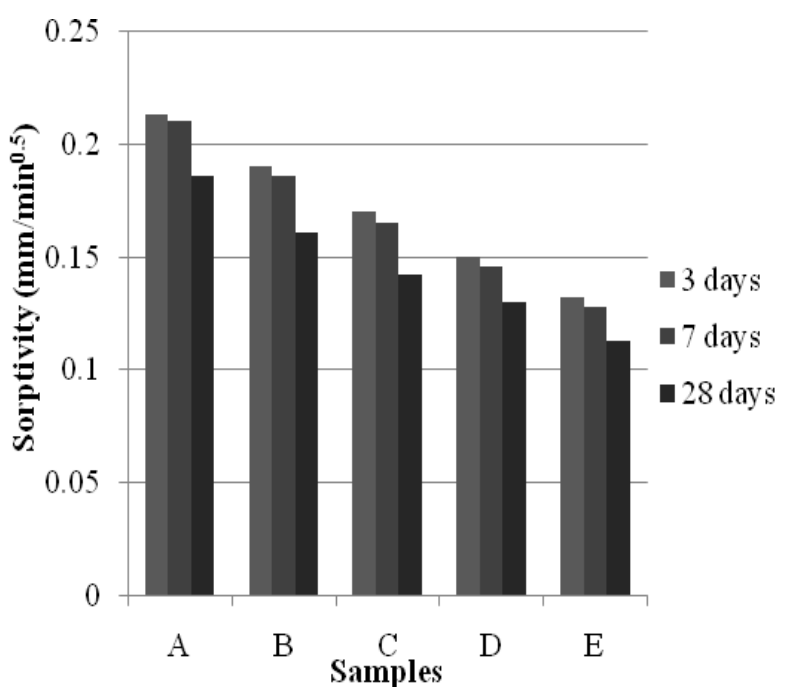

Figure 6: Sorptivity for different samples under air-dry curing

\subsection{Water absorption}

Water absorption is defined as the transport of liquids in porous solids caused by surface tension acting to the capillaries [18]. The water absorption of the EPS RHA concrete bricks at 3, 7 and 28 days under full water and air-dry curing are presented in Figure 7 and Figure 8.

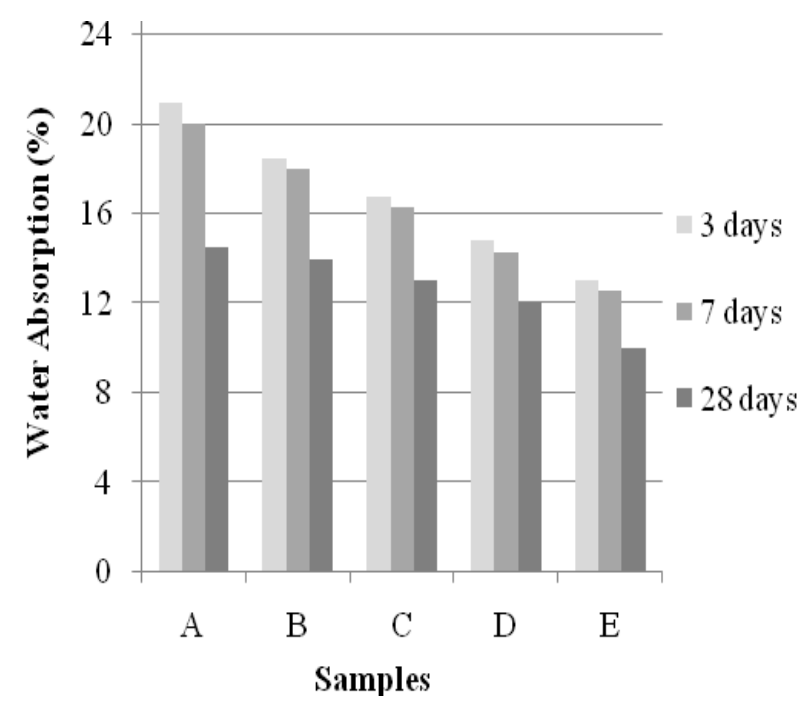

Figure 7: Water absorption for different samples under full water curing 


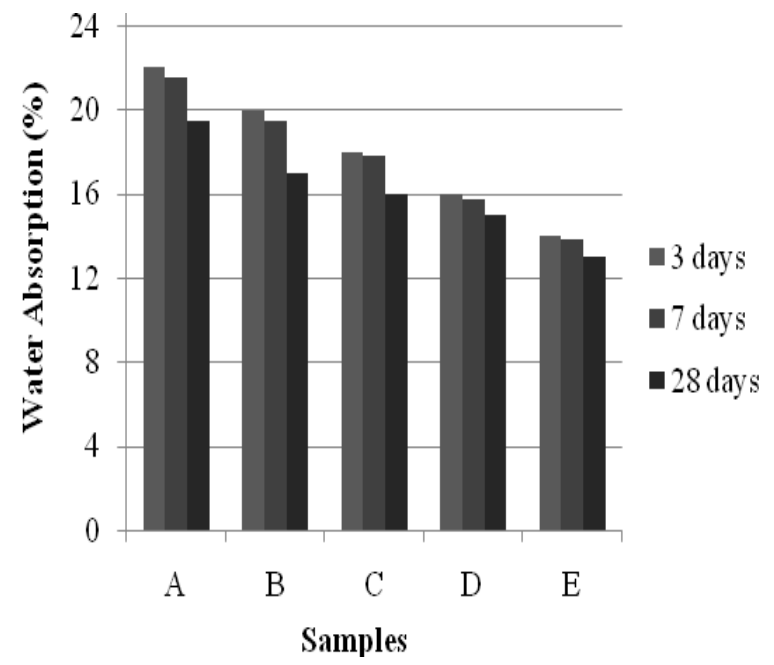

Figure 8: Water absorption for different samples under air-dry curing

The results showed that the full water curing produced the lowest percentage of water absorption for all samples as compared to the same samples under air dry curing. It was also observed that an increase in RHA replacement reduced the water absorption values. The water absorption value under full water and air dry curing at 28 days were in the range of $10-14.5 \%$ and $13-19.5 \%$ respectively. These values compare well with those of the lightweight concrete with pumice aggregates and pumice concrete, which have absorption values of $14-22 \%$ [19] and 19.1-22.2\% [20] respectively.

\subsection{Thermal conductivity}

Thermal conductivity is the measurement of the ability of a substance to conduct heat, determined by the rate of the heat flow. Figure 9 and Figure 10 show the thermal conductivity values of the EPS RHA concrete bricks at 3, 7 and 28 days under full water and air-dry curing conditions. Figure 8 shows the relationship between the thermal conductivity of samples cured under full water curing and concrete density.

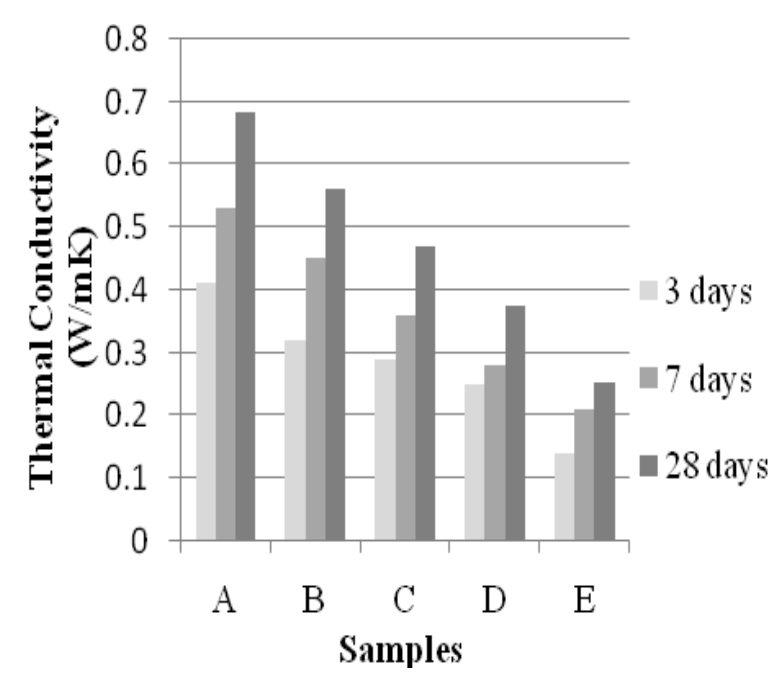

Figure 9: Thermal conductivity for different samples under full water curing

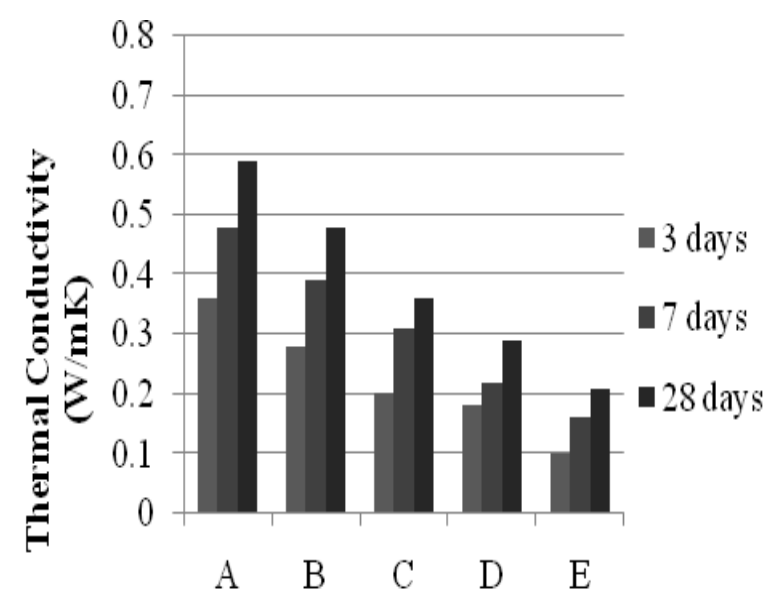

Samples

Figure 10: Thermal conductivity for different samples under air-dry curing

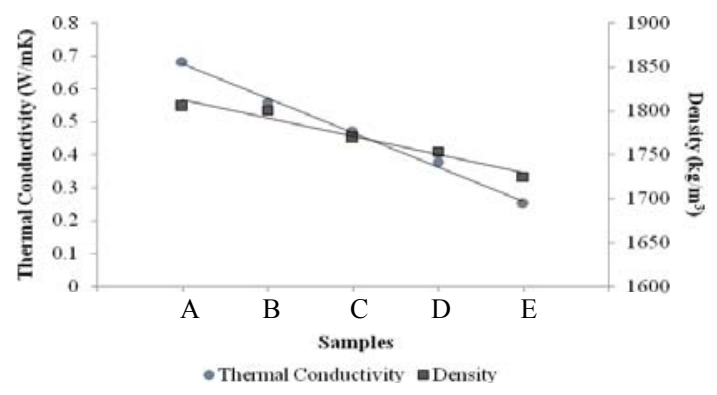

Figure 11: Relationship between thermal conductivity of samples cured under full water curing and 28day air-dry hardened concrete density. 
From Figure 11, it can be observed that the thermal conductivity decreases as the density of the samples reduced. Previous researchers have also reported that the thermal conductivity generally decreases as the density decreases [21]. EPS has a low thermal conductivity value of between $0.36-0.46$ $\mathrm{W} / \mathrm{mK}$ [22]. Therefore, the combined effects of the porous nature of RHA and the low thermal conductivity of raw EPS beads resulted in the lower thermal conductivity of the bricks. Air-dry curing produced concrete bricks with lower thermal conductivity. The thermal conductivity values under full water and air-dry curing at 28 days were in the range of $0.254-0.682 \mathrm{~W} / \mathrm{mK}$ and $0.21-0.59 \mathrm{~W} / \mathrm{mK}$ respectively. Sample C (10\% RHA) under full water curing reduces the thermal conductivity by approximately $31 \%$ as compared to control sample A, which is encouraging for higher energy saving potential in residential applications.

\section{Conclusions}

EPS RHA lightweight 'Green' concrete bricks not only can be considered as environmentally friendly building materials but also shows better energy savings. Based on the experimental results of this investigation, it can be concluded that:

1. The slump, fresh density and air content for EPS RHA concrete bricks was in the range of $65-100 \mathrm{~mm}, 1750-1838 \mathrm{~kg} / \mathrm{m}^{3}$ and $5.2-$ $6.9 \%$ respectively.

2. Sample C with 10\% RHA replacement showed the highest compressive strength of $17.51 \mathrm{~N} / \mathrm{mm}^{2}$ at 28 days under the full water (C1) curing condition. Further replacement of RHA decreases the compressive strength of the samples.

3. All brick specimens conformed to MS 76:1972 [12] as class 1 load bearing brick.

4. The sorptivity values for lightweight concrete bricks under full water and air-dry curing at 28 days were in the range of $0.075-0.145 \mathrm{~mm} / \mathrm{min}^{0.5}$ and $0.113-0.186$ $\mathrm{mm} / \mathrm{min}^{0.5}$ respectively.

5. The water absorption for lightweight concrete bricks under full water and air dry curing at 28 days were in the range of 10 $14.5 \%$ and $13-19.5 \%$ respectively.

6. The increase in the RHA content produced lower thermal conductivity values as compared to the control mix, sample A. The thermal conductivity decreases as the density of the samples reduced. The thermal conductivity values for lightweight concrete bricks under full water and air-dry curing at 28 days were in the range of $0.254-0.682$ $\mathrm{W} / \mathrm{mK}$ and $0.21-0.59 \mathrm{~W} / \mathrm{mK}$ respectively.

\section{Acknowledgments}

This project was funded by UNIMAS research 'Small Grant Scheme' under grant no. 02(S50)/715/2010(01). The first author is a Masters candidate supported by zamalah scholarship under scholarship no. MOSTI/BMI/TAJ/1-2 Jld 11 (7).

\section{References}

[1] P. K. Mehta, "The chemistry and technology of cement made from rice husk ash," In: Proceeding of UNIDO/ESCAP/RCTT workshop on Rice husk ash cements, Peshamar, Pakistan. Bangalore (India): Regional Centre for Technology Transfer, 1979, pp. $113-122$.

[2] RILEM. Committee 73-SBC final report, "Siliceous by-products for use in concrete," Material Structural, 21(121), 1998, pp. 69-80.

[3] G. M. Parton, M. E. Shendy-El-Barbary, "Polystyrene bead concrete properties and mix design," International Journal of Cement Composites and Lightweight Concrete, 4(3), 1982, pp. 153-161.

[4] D. J. Cook, "Expanded polystyrene concrete, concrete technology and design," In: R.N. Swamy, Editor, New Concrete Materials, Surrey University Press, London, 1, 1983, pp. 41-69.

[5] ASTM C 618, 2008, Standard Specification for Coal Fly Ash and Raw or Calcined Natural Pozzolan for Use in Concrete.

[6] MS 522: Part 1: 2003. Portland Cement (Ordinary And Rapid-Hardening): Part 1: Specification (Second Revision)

[7] ACI 213R, 1987, Guide for Structural Lightweight Aggregate Concrete, ACI Manual of Concrete Practice, Detroit: American Concrete Institute.

[8] BS1881: Part102: 1983, Method for Determination of Slump. London: British Standard Institution.

[9] BS 1881:Part 107:1983, Method for Determination of Density of Compacted Fresh Concrete, London: British Standard Institution.

[10] ASTM C 231, 2003, Standard Test Method for Air Content of Freshly mixed Concrete by The Pressure Method.

[11] MS 76:1972, Specifications for Bricks and Blocks of Fired Brick-earth Clay or Shale, SIRIM Malaysia Standard, Part 2: Metric Units.

[12] S.Y.N. Chan and X. Ji, "Water sorptivity and chloride diffusivity of oil shale ash concrete," Construction and Building Materials 12(4), 1998, pp. 177-183

[13] E.P. Kearsley and P.J. Wainwright, "Porosity and permeability of foamed concrete," Cement and Concrete Research, 31(5), pp.805-812.

[14] ISO 8301:1991. Thermal Insulation-Determination of Steady-state Thermal Resistance and related Properties- Heat Flow Meter Apparatus.

[15] A. A. Boeteng and D. A. Skeete, "Incineration of rice hull for use as a cementitious material," The Guyana Experience, Cement and Concrete Research, 20(5), 1990, pp. 795-802.

[16] H. Mahmud, M.F. A. Malik and M.F.M. Zain, "Effect of rice husk ash on strength and durability of binary and ternary blended concrete," Proceedings of 4th International Conference on Construction Materials (CONMAT 09), Nagoya, Japan, 2009, pp 533-539. 
[17] J.R. Philip, "The theory of infiltration, part 4, sorptivity and algebraic infiltration equations," Soil Science, 84(3), 1957, pp.257-264.

[18] J. M. Khatib and P. S. Mangat, "Influence of hightemperature and low-humidity curing on chloride penetration in blended cement" Cement and Concrete Research, 32(11), 2002, pp.1743-1753.

[19] L. Güdüz, and İ. Uğur, "The effects of different fine and coarse pumice aggregate/cement ratios on the structural concrete properties without using any admixtures," Cement and Concrete Research, 35(9), pp.1859-1864.

[20] D. Sari and A. G. Pasamehmetoglu, "The effect of gradation and admixture on the pumice lightweight aggregate concrete," Cement and Concrete Research, 35(5), pp.936-942.

[21] K. Lu-shu, S. Man-qing, S. Xing-Sheng and L .Yunxiu, "Research on several physicomechanical properties of lightweight aggregate concrete," International Journal of Lightweight Concrete, 2 (4), 1980, pp.185- 191.

[22] K. T. Yucel, C. Basyigit and C. Ozel, "Thermal insulation properties of expanded polystyrene as construction and insulating materials," 15th Proceeding of Symposium on Thermophysical Properties, in Boulder, Colorado, NIST/ASME, pp.54-66. 